\title{
The Effects Of Education On Alabama's Violent Crime Rate
}

\author{
https://doi.org/10.21272/sec.5(2).5-14.2021.
}

Richard Fast, ORCID: https://orcid.org/0000-0002-9779-1659

M.A. Economics 2021, Troy University, USA

\begin{abstract}
This paper summarizes the arguments and counterarguments within the scientific discussion on the issue of the effect of education on violent crime, specifically in the U.S. state of Alabama. The main purpose of the research is to determine whether more education leads to a decrease in the rate of violent crime. Systematization of the literary sources and approaches for reducing the violent crime rate indicate that increasing education, particularly the number of people with at least a high school or associate's degree, can be one influential tool in cutting crime. The relevance of this scientific problem analysis is that Alabama has one of the highest violent crime rates in the United States according to crime watch sources, and Alabama residents desire safer neighborhoods. Investigation of what effect education has on crime in the paper is carried out in the following logical sequence: Introduction, literature review, data and analysis, and conclusion. Methodological tools of the research methods include econometric analysis using log-linear, linear-log, and log-log models covering population, educational attainment, violent crime rate, and unemployment rate of each county over five years: 2011-2015. The object of research are all the counties of Alabama, because namely they have some of the highest crime rates in the United States. Coincidentally, Alabama also has one of the lowest educational attainment rates in the country; the average American has more years of formal schooling than the average Alabama resident, and the crime rates of all other U.S. states compared to Alabama reflect this important fact. The paper presents the results of an empirical analysis of how more education impacted the violent crime rate in that state, which showed that, with one exception, more years of schooling does indeed result in less violent crime. The research empirically confirms and theoretically proves that, in the majority of cases, a better educated populace is less likely to commit violent crime. The results of the research can be useful for educators, law enforcement, and criminal justice practitioners.
\end{abstract}

Keywords: education, crime, Alabama, crime rate, college education, high school, graduation rate, crime deterrence, schooling, public safety.

JEL Classification: H51, H52, H53, H75.

Cite as: Fast, R. (2021). The Effects Of Education On Alabama's Violent Crime Rate. SocioEconomic Challenges, 5(2), 5-14. https://doi.org/10.21272/sec.5(2).5-14.2021.

Received: 31.03 .2021

Accepted: 14.05.2021

Published: 25.06 .2021

Copyright: (C) 2021 by the author. Licensee Sumy State University, Ukraine. This article is an open access article distributed under the terms and conditions of the Creative Commons Attribution (CC BY) license (https://creativecommons.org/licenses/by/4.0/).

\section{Introduction}

Crime is a problem everywhere, however Alabama ranks \#43 overall on a list of safest states in the U.S., according to a May 14, 2018 study by U.S. News [17]. The same study found that Alabama is \#38 in low property crime and \#44 in low violent crime rate. At the same time, Alabama also trails the rest of the U.S. when it comes to educational attainment. According to one study, "About 24 percent of Alabamians have at least a college degree, a figure about 9 percentage points lower than the U.S. average [11]" Given these statistics, this paper will explore whether we can reduce violent crime rates in the state through educational attainment. This paper seeks to demonstrate that as Alabamians spend more time in school, particularly in the five-year period between 2011 and 
2015, their marginal propensity to commit a violent crime decreases. Thesis: On the average, as educational attainment increases, the violent crime rate in Alabama decreases.

First, we must define our terms. A "crime" is the breaking of a law that involves a victim. A breaking of a law that has no victim is not considered a crime in this study. "Violent crime" refers to the following, according to the Federal Bureau of Investigation's Uniform Crime Reporting System: murder, non-negligent manslaughter, forcible rape, and aggravated assault. The "crime rate" refers to how many crimes occur per 1,000 people. Typically, the scale is per 100,000 people, however this has been altered to take into account the county with the smallest population, which is Greene with 8,533. The county with the largest population is Jefferson at 659,460 [8].

Why do people turn to crime? Lochner (2007) reports that crime tends to follow trends in employment-- when unemployment rises, so does crime [19]. Linked to unemployment is the issue of poverty. The causes of poverty are outside the scope of this paper. Although, future research might explore the effects of statewide poverty on crime and educational attainment. An institutional analysis of why crime rates might increase with a less educated populace might be that less educated people do not know how property rights work and if they knew how to save and allocate capital, they would be able to start businesses and engage in entrepreneurship.

To give some background information, the 2010 U.S. Census shows that $82.1 \%$ of Alabama residents had a high school education or higher, with a $0.4 \%$ margin of error. The Census goes on to say that $21.9 \%$ of Alabama residents had a bachelor's degree or higher, with a $0.4 \%$ margin of error [11]. This paper tests for the average effect of a high school education on the crime rate and the effect of a bachelor's degree on the crime rate. The paper also looks at the effect of community colleges and two-year colleges, but not trade schools, as a form of developing one's job skills and furthering one's occupational education. A 2013 report by the Alliance for Excellent Education states, "According to the most recent data from the U.S. Bureau of Justice, 56 percent of federal inmates, 67 percent of inmates in state prisons, and 69 percent of inmates in local jails did not complete high school. Additionally, the number of incarcerated individuals without a high school diploma is increasing over time [4]."

Intuition [citation] tells us that as a person spends more years in school, they are exposed to more opportunities and have more options, rather than reverting to violent crime and force for getting what they want. This paper will seek to demonstrate empirically that as years of schooling changes, Alabama's violent crime rate fluctuates accordingly, holding other factors constant. Other factors that future research could take into account are population over time, age, sex, and race. An important note to keep in mind is that while more years of schooling may lead to a decrease in crime, it may not be the only factor. There might be other factors at play aside from time spent in a classroom that lead someone to forgo criminal activity. These factors might include the opportunity cost of other endeavors such as spending time with family as opposed to the possibility of spending time in jail.

The paper will be structured as follows: Section II will give a brief over-view of the existing literature on crime and education rates, as well as the economic theory used to support the models presented here. Section III will explain the hypothesis we are seeking to test. We will explore the relationship between years of education and crime rates in the state of Alabama. Our hypothesis is that as the average statewide years of schooling goes up, the average statewide rate of violent crime goes down, using a sample size of 67 counties over a span of five years: 2011-2015. Our null hypothesis is that an increase in years of education has no effect on statewide violent crime rates. Section IV will be the results and discussion portion. For discussion, we will lay out some public policy implications. We will also provide a table of summary statistics for every variable. Section $\mathrm{V}$ will be a conclusion summarizing the models used, why the information they convey is important, as well as some possibilities for future research ideas.

\section{Literature Review and Theory}

The following is a review of the current literature regarding violent crime and education rates in Alabama. The general trend in the literature is that more education reduces the over all crime rate in any population, not only in Alabama. The reasons for this are varied and can depend on individual circumstances. Using economic theory, we can infer that more education is a positive externality on society and that each additional year of education 
makes that individual more productive, which has net-positive benefits for both the individual in terms of higher wages and community in terms of more output. Education, then, has been viewed as a means of evidence-based crime prevention. We examine some examples and studies here.

According to the executive summary of "Education as Crime Prevention: The Case for Reinstating Pell Grant Eligibility for the Incarcerated" by Daniel Karpowitz and Max Kenner, "This report illustrates the overwhelming consensus among public officials that postsecondary education is the most successful and cost-effective method of preventing crime [13]." The take away message is that simply having a high school education is not enough to deter crime; postsecondary education increases the chances of seeking non-crime related methods of doing things. Another implication is to encourage the remedial education of inmates after they have been incarcerated for a violent crime. Increasing a felon's education greatly reduces the chances of him or her going back to jail once released (Chen, 2015).

Another study looked at the effect crime had on Alabama's farms. In his paper "Crime and Alabama Farms", John Edward Dunkelberger explores how rural crime has changed the way Alabama communities keep their property secure, particularly since the 1980's [11]. One of the solutions that his paper proposes is to increase security through neighborhood watch programs as an alternative to government programs.

In his 2007 essay "Education and Crime", Lance Lochner finds that an increase in education leads to an increased opportunity cost for prospective criminals from engaging in higher pay, low risk legitimate work and enhancing their social networks in more prestigious atmospheres. He also finds that finishing high school not only makes it less likely for young men to commit crimes, but it also helps to "socialize" them to fit in with society. In particular, Lochner shows "In the 1980 wave of the National Longitudinal Survey of Youth (NLSY), 34\% of all men ages 20-23 with 11 or 12 years of completed schooling self-reported earning some income from crime, compared with $24 \%$ of those with a high school degree, and only $17 \%$ of those with more than twelve years of school (Lochner 2004)." Although that was a national survey, the results should not be too different for Alabama.

The survey referenced above finds that while finishing high school curbs violent crime and property crime, however as the level of education increases so-called "white collar" crime remains an issue. Groot, Wim, and van den Brink (2010) state "We find that the probability of committing crimes like shop lifting, vandalism and threat, assault and injury decrease with years of education. The probability of committing tax fraud, however, increases with years of education [4]." This is in line with our hypothesis that more education cuts down on violent crime, but does not address other types of non-violent crime.

Lochner continues to address some of the problems with empirical and data oriented approaches to studying the negative correlation between crime and education: "Individuals who choose more schooling (even after conditioning on observable characteristics) might also choose less crime regardless of their education level, in which case regressionbased estimates do not identify the causal effect of schooling on crime." Lochner goes on to say, "using variation in crime and education across states or local communities may also produce biased estimates. Governments may face a choice between funding law enforcement and good public schools, which would tend to produce a spurious positive correlation between education and crime." This is an important point to keep in mind when analyzing the data; there might be other variables at work that have not or cannot be accounted for (omitted variable bias). Finally, Lochner cautions that "....reverse causality is another important concern, in which case traditional regression estimates may be confounded by the effect of criminal activity on schooling." In conclusion, Lochner asserts that "Lochner and Moretti (2004) estimate that a one percent increase in high school graduation rates would save the U.S. economy nearly $\$ 2$ billion from reduced costs associated with criminal activity. The social savings per additional male graduate from crime reduction alone amounts to $\$ 1,600-2,900$, or $14-26 \%$ of the private return to individuals from increased earnings." The financial losses due to violent crime in Alabama creates an incentive to invest more in public education to stem the flow of violent criminal criminals into the state prison system. How effective the Alabama public education system is in deterring violent crime, regardless of more money, would be a topic for future research. This study does not incorporate quality of education in Alabama, simply what effect of having a high school diploma or college degree has on the marginal propensity to commit a violent crime in the state.

Another consideration is that some individuals plan a career in crime simply because they are good at it, regardless of the amount of time spent in a classroom. In Alabama, one might consider professional criminal organizations, such as 
the Dixie Mafia. This broadens the question to how the public in Alabama views proper solutions to violent crime. Alabama has a reputation for being a state that is "hard on crime", which began during the Reagan years in the 1980s. A 2009 report found that the public preferred hard punishment, as opposed to remedial high school education, as the most favorable way to deal with violent crime [6]. Other studies might explore whether the death penalty deters violent crime in Alabama and what effect education might have on whether convicts receive the death penalty. This approach of responding to violent crime with violent punishment has been disputed as an effective crime deterrent. Other studies suggest that increasing convicts' educational attainment is a more effective way of stopping and preventing future violent crime both by current convicts and potential convicts. (Chen, 2015).

With the view that more time in the classroom means less time contemplating crime, various governments have experimented with lengthening the period of compulsory education. Compulsory education is the minimum amount of years by law students are required to attend school. Machin, Marie, and Vujic (2012) state, "The causal crime reducing effect of education is estimated to be negative and significant, and considerably bigger in (absolute) magnitude than ordinary least squares estimates [15]." For example, in the 1980's, the U.K. experimented with prolonging compulsory education as a means of preventing crime, with positive results. There are benefits and drawbacks to prolonging compulsory education. Machin, Marie, and Vujic (2012) also reported that "[t]he education boost also significantly impacted other productivity-related economic variables (qualification attainment and wages), demonstrating that the incapacitation effect of additional time spent in school is not the sole driver of the results" of less crime[15]. One of the drawbacks is, if a student is uninterested in learning and can demonstrate that he and/or his family would be better off by him working, and he can prove that he can do well in the workplace, then staying in school might be doing him more harm than good. If that is the case, crime is not a concern for this individual. However, that would have to be examined by the school on a case by case basis.

\section{Data and Model}

The dependent variable is the violent crime rate for each respective county from the years 2011-2015. The independent variables we are using for the model are population for each respective county, percent who have a college education (defined as at least an associate's degree), percent who have graduated from high school, and the unemployment rate for each respective county. The timeframe we are using is within the span of five years, from 2011 to 2015 . The reason we are using that particular decade is because that is what the most current data there is in the U.S. Census. The data for 2019 are incomplete. Perhaps a later study could take the 2020 U.S. Census into account.

Hypothesis. The hypothesis we want to test. $\mathrm{H}_{\mathrm{O}}: \beta_{1}=0$ and $\mathrm{H}_{\mathrm{A}}: \beta_{1} \neq 0$, or $<0$. If we fail to reject our null and it is 0 , that means that there is a positive correlation between a higher level of education and a lower rate of crime. If we reject the null, that means that we adopt our alternate hypothesis which states that that there is not a positive correlation between a higher level of education and a lower rate of crime. In other words, there is a negative correlation between the level of education and the crime rate. From here, we evaluate our T critical value which is found by seeing whether the absolute value of the t-statistic ([actual - hypothesis] / standard error), is greater than the absolute value of the critical value. The result will tell us if it is statistically significant and whether to reject the null. There is the possibility of a Type I error-- when we reject the null when it is in fact true; in other words, a false positive. There is also the possibility of a Type II error-- a non-rejection of the null when it is in fact false; a false negative. We reject the null when the probability of estimate of mean is at less than $5 \%$ significance level; that is, $2.5 \%$ on either side of the tails. Failing to reject the null is preferable because heteroskedasticity is a perpetual problem in the data. Here, we have clustered robust standard errors, which assumes that our residuals are independent of one another.

First, as a starting point, I collected data on the population on all the counties in Alabama from the 2010 U.S. Census. The population data was collected from factfinder.census.gov [2]. Then, I collected data on what percentage of the population in each county had a bachelor's degree or higher, and the high school graduation rate. The high school graduation percentage for each county from 2011 to 2015 was obtained from the Alabama Department of Education [5]. The data for the graduation rate is in percentage terms. The data of those that had no high school diploma was obtained from "Educational Attainment by County in Alabama" on StatisticalAtlas.com [9]. Next, I collected the data of the percentage of the population in each county with a college education; that is, with at least an associate's degree [16]. Next, I collected the unemployment rate, in percentage terms, from each county from 2013 to 2015 [14]. For years 
2012 and 2011, I collected data from the U.S. Bureau of Labor Statistics [20]. Next, I collected the number of violent crimes in each county from 2011 to 2015 [18].

One interesting observation to note was the change in population numbers from one metropolitan county to another. For example, from 2011 to 2015, Montgomery, the capital, saw a drop in population, while Tuscaloosa and Shelby counties saw a rise in population. This might be due to natural disasters in the area.

Model specification. Crime $_{i}=\beta_{\mathrm{o}}+\beta_{1}$ educ $_{1}+\mathrm{U}_{\mathrm{i}}$. This template model seeks to tell us what effects a one-unit change in education has on the violent crime rate. Crime is our dependent variable. $\beta_{0}$ is our constant. $\beta_{1}$ educ ${ }_{1}$ is the independent variable representing level of education; either high school or college, or both. And, $\mathrm{U}_{\mathrm{i}}$ is our error term, which includes all omitted variables. The data for high school graduation rates and population that has a college education are in percentage terms. Using that model as a template, we add in other independent variables such as population per county and the unemployment rate for each county in the years 2011-2015.

\section{Methodology}

We use a linear log model to show that as $\mathrm{x} \%$ of the population receives more years of education, the overall crime rate decreases by $\mathrm{z} \%$. This relationship is represented by ${ }^{\wedge} \mathrm{Crime}=557.8+3642 \ln$ (educ) $+\mathrm{U}_{\mathrm{i}} .{ }^{\wedge} \mathrm{Crime}$ is the estimated rate of crime. 557.8 is our constant. $3642 \mathrm{ln}$ (educ) is the rate of change in years of education. $\mathrm{U}_{\mathrm{i}}$ is our error term.

We also use a log-linear model, which is the reverse of a linear log model. Here, $100\left(\beta_{1}\right)$ represents that a one unit change in education, either high school or college or both results in $100\left(\beta_{1}\right) \%$ change in the violent crime rate. This relationship is represented by $\ln \left({ }^{\wedge} \mathrm{Crime}\right)=2.811+.0096$ (educ) $+U_{i}$. This model tells us that a one-year increase in education leads to a $.96 \%$ increase in crime- the opposite of what we expected. We expected that as the population increases their educational attainment, the overall crime rate in the state would decrease.

We use a log-log model, in which both the dependent (violent crime rate) and independent variable (education) change in $\%$ terms. For example, a $1 \%$ increase in our independent variable, such as high school graduation rate, results in a $1 \%$ decrease or increase in our dependent variable, violent crime. Here, a $1 \%$ increase in the high school graduation rate results in a $0.3642 \%$ decrease in crime for Table 1 . This model tells us the elasticity of the demand for education as it relates to the rate of crime. Here, we take the \% change in our dependent variable, violent crime, over the $\%$ change in our independent variable, the high school graduation rate alone which will be covered in Table 1, the percentage of adults with a college education in which will be covered in Table 2, and both which will be covered in Table 3 . In economics, this is the same concept as the $\%$ change in quantity demanded over the $\%$ change in price, such as the income effect and the substitution effect.

These tables help determine the standard error, the z-score, the p-lims, t-statistic, SST, standard deviation from the mean from each model. In this model, we examine panel data only. Subsequent studies could use cross sectional and time series data as a method of tracking the results of changes in education on violent crime over different periods of time. Using an f-test we are able to determine statistical significance, which, from the tables, show us that the models are statistically significant.

There are some potential problems with the models used. One problem is solving for a multicollinearity problem. That is, if Corr $\left(\mathrm{X}_{1}, \mathrm{X}_{2}\right)=1$, then one of the variables should be omitted. There is risk of omitted variable bias. If correlation is greater than .8 , the model is justified in excluding a variable. Another possibility would be to increase the sample size, which would require increasing the size and scope of the study; there are only 67 counties in Alabama. Because there is no direct way to measure or test for multicollinearity, this study focuses on the correlation between $X_{1}$ and $X_{2}$. In this case, we can account for that in our model by altering it to $\left(\mathrm{X}_{1}, \mathrm{X}_{2}, \mathrm{X}_{3}\right)$. Collinearity could be a problem. Regarding the variables in the model above, it could be between the high school graduation rate and the percentage of the population with a college degree. Another thing to take into account might be the Variance Inflation Factor (VIF), which is $1 / 1-R_{j}^{2}$. Because the $\mathrm{R}^{2}$ was omitted from the regression tables, a future study might take more years into account, such as between 2010 and 2020, which might include the $\mathrm{R}^{2}$ and include the VIF. 
Interpretation. The data for high school graduation rates are, by definition, in percentage terms, since we are looking at the portion of the population. On the other hand, the population as the independent variable is expressed in raw numbers.

\section{Results and Discussion}

The following are some are some possible flaws in this research project. The first is the possibility of omitted variable bias. If this is the case, then there would be a biased estimator. If the variables are correlated, then there is a problem. On the other hand, if the variables are not correlated, then there is no problem. The second is the possibility of including an irrelevant variable. If this is the case, then there would be inefficient estimators. The third is having perfectly correlated variables, otherwise known as multi-collinearity. Also, by including more variables, we lose more degrees of freedom. This is problematic because it means that we lose accuracy in our estimate and confidence interval.

Table 1, below, is a chart of four regressions. The first was using violent crime as the dependent variable and the high school graduation rate as the only independent variable. The second was using violent crime as the dependent variable and the high school graduation rate and county unemployment rate as the independent variables. The third regression used the violent crime rate as the dependent variable and the high school graduation rate and the population of each county as the independent variables. The fourth regression used the violent crime rate as the dependent variable and the high school graduation rate, the population of each county, and the unemployment rate of each county as the independent variables.

Table 1. Effect of High School Education on AL County Crime Rate

\begin{tabular}{|c|c|c|c|c|}
\hline & (1) & (2) & (3) & (4) \\
\hline & VIOCRIM & VIOCRIM & VIOCRIM & VIOCRIM \\
\hline \multirow[t]{2}{*}{ hsgradrate } & -0.518 & -2.846 & -5.227 & -1.538 \\
\hline & $(-0.04)$ & $(-0.25)$ & $(-0.72)$ & $(-0.21)$ \\
\hline \multirow[t]{2}{*}{ 2011.YEAR } & 0 & 0 & 0 & 0 \\
\hline & (.) & (.) & (.) & (.) \\
\hline \multirow[t]{2}{*}{ 2012.YEAR } & 61.88 & -152.6 & 77.77 & $192.6^{* * * *}$ \\
\hline & $(1.29)$ & $(-1.28)$ & $(1.84)$ & $(4.10)$ \\
\hline \multirow[t]{2}{*}{ 2013.YEAR } & $-542.0^{*}$ & $-832.6^{*}$ & $-505.0^{*}$ & $-358.3^{*}$ \\
\hline & $(-2.38)$ & $(-2.47)$ & $(-2.43)$ & $(-1.97)$ \\
\hline \multirow[t]{2}{*}{ 2014.YEAR } & -537.1 & $-885.4^{*}$ & $-476.6^{*}$ & -311.4 \\
\hline & $(-1.96)$ & $(-2.21)$ & $(-2.04)$ & $(-1.53)$ \\
\hline \multirow[t]{2}{*}{ 2015.YEAR } & -534.7 & $-972.3^{*}$ & -465.1 & -256.4 \\
\hline & $(-1.77)$ & $(-2.13)$ & $(-1.87)$ & $(-1.19)$ \\
\hline \multirow[t]{2}{*}{ unemploymentrate } & & $-114.3^{*}$ & & $61.71^{*}$ \\
\hline & & $(-2.41)$ & & $(2.52)$ \\
\hline \multirow[t]{2}{*}{ POPULATION } & & & $0.0108^{* * *}$ & $0.0113^{* * *}$ \\
\hline & & & $(6.32)$ & $(6.72)$ \\
\hline \multirow[t]{2}{*}{ cons } & 871.7 & $2323.1^{*}$ & 4332 & -5707 \\
\hline & $(1.05)$ & $(2.53)$ & $(0.79)$ & $(-0.80)$ \\
\hline$N$ & 325 & 325 & 325 & 325 \\
\hline
\end{tabular}

Notes: $t$ statistics in parentheses. ${ }^{*} p<0.05,{ }^{* *} p<0.01,{ }^{* * *} p<0.001$. Results for fixed effects not shown.

Source: original regression.

Discuss results from Table 1. As the high school graduation rate increased each year per county, the violent crime rate decreased. This result confirms our hypothesis that a more educated population is less likely to commit crime. 
However, we also saw that as the amount of the college educated population increased, the violent crime rate increased as well. This result counters our hypothesis that as the educational attainment rate increases, the violent crime level decreases. The reasons for this are explored in Table 3, which saw similar results.

What we see is that as the high school graduation rate increases by one percent,

the number of violent crimes decreases by 31.58 . The following is the equation used to derive this result.

$\beta_{H S}=\underline{\Delta \text { Violent Crime }}$

\section{$\% \Delta$ High School Graduate}

The independent variable ßhighschool is defined as the change in the number of violent crimes per year divided by the percentage change in high school graduates. The R-squared was omitted from the table.

Table 2, below, is a chart of four regressions. The first used violent crime as the dependent variable and college education as the independent variable. The second regression used violent crime as the dependent variable and college education and the unemployment rate as the independent variables. The third regression used violent crime as the dependent variable and college education and population of each county as the independent variables. The fourth regression used violent crime as the dependent variable and college education, population of each county, and the unemployment rate of each county as the independent variables.

Table 2. Effect of College Education on AL County Crime Rate

\begin{tabular}{|c|c|c|c|c|}
\hline & (1) & (2) & (3) & (4) \\
\hline & VIOCRIM & VIOCRIM & VIOCRIM & VIOCRIM \\
\hline collegeedu & $\begin{array}{l}57.46^{*} \\
(2.38)\end{array}$ & $\begin{array}{l}54.37^{*} \\
(2.37)\end{array}$ & $\begin{array}{c}-44.69^{* * *} \\
(-4.17)\end{array}$ & $\begin{array}{c}-40.82^{* * * *} \\
(-3.76)\end{array}$ \\
\hline 2012.YEAR & $\begin{array}{l}0 \\
\text { (.) }\end{array}$ & $\begin{array}{l}0 \\
\text { (.) }\end{array}$ & $\begin{array}{l}0 \\
\text { (.) }\end{array}$ & $\begin{array}{l}0 \\
\text { (.) }\end{array}$ \\
\hline 2013.YEAR & $\begin{array}{c}-686.1^{* * *} \\
(-3.26)\end{array}$ & $\begin{array}{c}-699.0^{* *} \\
(-3.24)\end{array}$ & $\begin{array}{c}-541.9^{* * *} \\
(-3.18)\end{array}$ & $\begin{array}{c}-527.3^{* * *} \\
(-3.07)\end{array}$ \\
\hline 2014.YEAR & $\begin{array}{c}-1141.7^{* * *} \\
(-2.91)\end{array}$ & $\begin{array}{c}-1144.3^{* *} \\
(-2.90)\end{array}$ & $\begin{array}{l}-185.0 \\
(-1.29)\end{array}$ & $\begin{array}{l}-184.7 \\
(-1.28)\end{array}$ \\
\hline 2015.YEAR & $\begin{array}{c}-641.1^{* * * *} \\
(-3.30)\end{array}$ & $\begin{array}{c}-690.6^{* * *} \\
(-3.20)\end{array}$ & $\begin{array}{l}-575.1^{\text {** }} \\
(-3.27)\end{array}$ & $\begin{array}{c}-516.1^{* *} \\
(-2.85)\end{array}$ \\
\hline Unemploymentrate & & $\begin{array}{l}-23.57 \\
(-1.29)\end{array}$ & & $\begin{array}{l}27.86^{*} \\
(2.27)\end{array}$ \\
\hline Population & & & $\begin{array}{c}0.0111^{* * * *} \\
(9.36)\end{array}$ & $\begin{array}{c}0.0112^{* * * *} \\
(9.47)\end{array}$ \\
\hline _cons & $\begin{array}{l}-23.34 \\
(-0.12)\end{array}$ & $\begin{array}{l}243.6 \\
(1.23)\end{array}$ & $\begin{array}{c}801.1^{\text {**** }} \\
(3.88)\end{array}$ & $\begin{array}{l}482.0 \\
(1.84)\end{array}$ \\
\hline$N$ & 264 & 264 & 264 & 264 \\
\hline
\end{tabular}

Notes: $t$ statistics in parentheses. ${ }^{*} p<0.05,{ }^{* *} p<0.01,{ }^{* * *} p<0.001$. Results for fixed effects not shown.

Source: original regression.

Discuss results from Table 2. What we see from the information in Table 2 is that violent crime shows all negative numbers for the years 2013, 2014, and 2015. This means that crime decreased in those years as a result of an increase in the percentage of the population that held a college degree. Why 2012 is all zeroes and why 2011 is omitted from the table is unknown. We have data for those years. Collinearity might be the reason; which Stata corrects for. This brought our sample size down from 325 to 264. The R-squared is omitted from the table.

Table 3, below, is a chart of four regressions. The first regression used violent crime as the dependent variable and the high school graduation rate of and percent of residents with a college education of each county as the independent variables. The second regression used violent crime as the dependent variable and the high school graduation rate, college education, and unemployment rate of each county as the independent variables. The third regression used violent crime as the dependent variable and the high school graduation rate, college education, and the population of each county as the independent variables. The fourth regression used violent crime as the 
dependent variable and the high school graduation rate, college education, population, and the unemployment rate of each county as the independent variables.

Table 3. Effect of High School \& College Education on AL County Crime Rate

\begin{tabular}{|c|c|c|c|c|}
\hline & (1) & (2) & (3) & (4) \\
\hline & VIOCRIM & VIOCRIM & VIOCRIM & VIOCRIM \\
\hline hsgradrate & $\begin{array}{l}-6.113 \\
(-0.55)\end{array}$ & $\begin{array}{l}-7.108 \\
(-0.65)\end{array}$ & $\begin{array}{l}-4.774 \\
(-0.98)\end{array}$ & $\begin{array}{l}-3.275 \\
(-0.66)\end{array}$ \\
\hline collegeedu & $\begin{array}{l}57.46^{*} \\
(2.39) \\
\end{array}$ & $\begin{array}{l}53.73^{*} \\
(2.32)\end{array}$ & $\begin{array}{c}-44.38^{* * * *} \\
(-4.12)\end{array}$ & $\begin{array}{c}-40.84^{* * *} \\
(-3.77)\end{array}$ \\
\hline 2012.YEAR & $\begin{array}{l}0 \\
(.)\end{array}$ & $\begin{array}{l}0 \\
\text { (.) }\end{array}$ & $\begin{array}{l}0 \\
\text { (.) }\end{array}$ & $\begin{array}{l}0 \\
\text { (.) }\end{array}$ \\
\hline 2013.YEAR & $\begin{array}{c}-664.2^{* *} \\
(-2.97)\end{array}$ & $\begin{array}{c}-676.3^{* *} \\
(-2.97)\end{array}$ & $\begin{array}{c}-525.6^{* *} \\
(-2.95)\end{array}$ & $\begin{array}{c}-517.0^{* * *} \\
(-2.89)\end{array}$ \\
\hline 2014.YEAR & $\begin{array}{c}-1089.1^{*} \\
(-2.50)\end{array}$ & $\begin{array}{c}-1083.7^{*} \\
(-2.49)\end{array}$ & $\begin{array}{l}-147.3 \\
(-0.93) \\
\end{array}$ & $\begin{array}{l}-158.9 \\
(-0.99) \\
\end{array}$ \\
\hline 2015.YEAR & $\begin{array}{l}-570.0^{*} \\
(-2.21)\end{array}$ & $\begin{array}{l}-618.2^{*} \\
(-2.27)\end{array}$ & $\begin{array}{l}-520.7^{*} \\
(-2.53)\end{array}$ & $\begin{array}{l}-482.4^{*} \\
(-2.33)\end{array}$ \\
\hline unemploymentrate & & $\begin{array}{l}-28.46 \\
(-1.78) \\
\end{array}$ & & $\begin{array}{l}26.13^{*} \\
(2.14)\end{array}$ \\
\hline POPULATION & & & $\begin{array}{c}0.0111^{* * * *} \\
(9.12)\end{array}$ & $\begin{array}{c}0.0111^{* * * *} \\
(9.27)\end{array}$ \\
\hline _cons & $\begin{array}{l}450.3 \\
(0.45) \\
\end{array}$ & $\begin{array}{l}849.6 \\
(0.89) \\
\end{array}$ & $\begin{array}{c}1167.2^{* * * *} \\
(3.37)\end{array}$ & $\begin{array}{l}753.0 \\
(1.81)\end{array}$ \\
\hline$N$ & 264 & 264 & 264 & 264 \\
\hline
\end{tabular}

Notes: $t$ statistics in parentheses. ${ }^{*} p<0.05,{ }^{* *} p<0.01,{ }^{* * *} p<0.001$. Results for fixed effects not shown.

Source: original regression.

Discuss results from Table 3. What we learn from the information in the third table is that while an increase in the high school graduation rate does lower the rate of violent crime, an increase in the college educated population does not do the same. There are several reasons why this might be the case. The first reason might be that because most people convicted of a violent crime lack a high school diploma, an increase in the education level of those who already do have a high school diploma are already less likely to commit a violent crime to begin with. The second reason might be that just because there is an increase in the percent of the population with a college degree does not ensure that the quality of education received is enough to deter violent crime. Still a third reason might be that natural disasters in those years, such as hurricanes and damaging thunderstorms, as Alabama is prone to, caused sufficient property damage to lead desperate undereducated population to increase violent crime to take care of unmet needs, as seen with Hurricane Katrina in New Orleans. Table 3 had the same issue as Table 2, in that Year 2011 and Year 2012 were eliminated, which brought down our sample size from 325 to 264 . However, the effects were still the same; the more educated the population, the more the violent crime rate decreased. The $\mathrm{R}$-squared was omitted from the data table.

Robustness Check. A robustness check for Table 1 showed that we had similarities in signs with the dependent and independent variables. A robustness check for Table 2 showed that we had similarities in signs with the dependent and independent variables. A robustness check for Table 3 showed that we had similarities in signs with the dependent and independent variables.

\section{Conclusion}

In conclusion, using economic analysis, the study confirmed that education is a positive externality on the public safety of the population in Alabama. Engaging in violent crime increases the opportunity cost of higher paying, legitimate jobs that do not involve the risk of jail time. The study's hypothesis proved correct; As residents of Alabama attain a higher level of education, the likelihood of committing a violent crime does down. We failed to reject the null because our $\beta_{1}$, depending on the particular model outlined above, high school graduation rate, percentage of the population with a college degree, population of each county, and the unemployment rate of each 
county was set equal to 0 . This allowed us to control for each of the independent variables individually and test each one's impact and effect on the violent crime rate. Using all 67 counties as a sample size, we see that as education lowers, crime increases, and as education rises, crime decreases. By holding certain variables constant, namely high school graduation rate and college education, the model used comparative statics to test the null hypothesis against the alternative hypothesis. We were able to prove our null hypothesis by showing that as the rate of high school graduation increased, the crime rate per county and statewide decreased. The most dramatic result we found was that high school graduation made the most dramatic difference in curbing and decreasing the violent crime rate. College education, in 2011, made a smaller difference, and, in 2012, actually had the opposite effect. Those years actually saw an increase in crime with an increase in the college educated population. What we can infer from this study is that policymakers should focus more on promoting high school graduation rather than college graduation in order to deter crime. Using economic theory to support our evidence from the models used above, the public policy implication is to increase Alabamians' average years of schooling in order to minimize its crime problem. Another implication is to encourage the remedial education of inmates after they have been incarcerated for a violent crime. Increasing a felon's education greatly reduces the chances of him or her going back to jail once released (Chen, 2015). As more of the population graduates from high school, they are less likely to go to jail in the first place. One point of emphasis for policymakers might be to not only focus on public safety, but also to explore paths of recovery for all violent criminals, but particularly those who did not graduate high school, so that the cycle of poverty, unemployment, and violent crime does not continue. This study suggests that a rise in the high school graduation rate will lower Alabama's violent crime rate, reduce the incarceration rate, and lower the propensity to engage in violent criminal activity due to the opportunity cost of higher-paying, legitimate jobs that an education assists in attaining.

What we found was that as the high school graduation rate increased between the years 2011 through 2015, there was a subsequent drop-off in the rate of violent crime. However, we also found that as the college graduation rate increased between that same time period, the crime rate actually increased by 31.58 .

Some possibilities for future research ideas include exploring the causes of poverty and its effects on the marginal propensity to commit a violent crime and its effects on educational attainment. Other future research might include the effects of monetary inflation on the crime rate and in relation to the level of education of the accused. Still more future research might take into account the economics of gang activity in the state and the effect that gangs have on the probability of academic success, particularly the likelihood of graduating high school. Research might include on what percentage of violent crimes are tied to gang activity and what effect an increase in education has on the violent crime associated with gang activity.

Funding: self-funded.

Author contribution: conceptualization: Richard Fast; data curation, Richard Fast; formal analysis, Richard Fast; funding acquisition, Richard Fast; investigation, Richard Fast; methodology, Richard Fast; project administration, Richard Fast; resources, Richard Fast; software, Richard Fast; supervision, Richard Fast; validation, Richard Fast; visualization, Richard Fast; writing - original draft, Richard Fast; writing - review \& editing, Richard Fast.

\section{References}

1. Alabama Counties by Population. Alabama-Demographics.com. Available at: [Link]. Referenced April 20, 2019.

2. Annual Estimates of the Resident Population: April 1, 2010 to July 1, 2016" factfinder.census.gov Posted July, 2016. Available at: [Link]. Accessed on April 20, 2019.

3. Chen, Michelle (2015). Prison Education Reduces Recidivism by Over 40 Percent. Why Aren't We Funding More of It? The Nation. Available at: [Link]. [Google Scholar]. Accessed April 28, 2019.

4. Crime Rates Linked to Educational Attainment (2013). Alliance Report Finds. Alliance for Excellence in Education. Available at: [Link]. Accessed on April 29, 2019. 
5. $\quad$ Data Center. Graduation Rate: 2016-2017. Alabama Department of Education. Posted June 11, 2013. Available at: [Link].

6. Doble, John and Josh Klein (2009). Punishing Criminals, the Public's View: An Alabama Survey. Federal Sentencing Reporter, 21(4), p. 291. Available at: [Link].

7. Dunkelberger, John Edward, et al. (1992). Crime and Alabama farms: Victimization, subjective assessment, and protective action. [Link], [Google Scholar].

8. Education Attainment for States, Percent with High School Diploma and with Bachelor's Degree: 2010. 2010 American Community Survey 1-Year Estimates Table S. 1501. Available at: [Link].

9. Educational Attainment by County in Alabama StatisticalAtlas.com. Available at: [Link]. Accessed April 21, 2019.

10. Ehrlich, Isaac (1975). On the relation between education and crime."Education, income, and human behavior. NBER, pp. 313-338. Available at: [Link].

11. Gore, Leada. "67 Alabama counties, ranked from most to least-educated" AL.com. Posted June 13, 2017. Available at: [Link]. Referenced April 20, 2019.

12. Groot, Wim, and Henriëtte Maassen van den Brink (2010). The effects of education on crime. Applied Economics, 42(3), 279-289. Available at: [Link], [Google Scholar]. Accessed April 23, 2019.

13. Karpowitz, Daniel, Max Kenner, and Bard Prison Initiative (1995). Education as crime prevention: The case for reinstating Pell Grant eligibility for the incarcerated. Evaluation, 1-8. Available at: [Google Scholar], [Link].

14. Local Area Unemployment Statistics. Alabama Department of Labor. Available at: [Link]. Accessed April 23, 2019.

15. Machin, Stephen, Olivier Marie, and Sunčica Vujić (2012). Youth crime and education expansion. German Economic Review, 13(4), 366-384. Available at: [CrossRef].

16. Percentage of Alabama residents (ages 25-64) with at least an associate degree, by county. Lumina Foundation. Published 2016. Available at: [Link]. Accessed April 24, 2019.

17. Public Safety Rankings: Measuring Crime Levels in Each State. Available at: [Link]. Referenced April 20, 2019.

18. Violent Crime. CountyHealthRankings.com. Available at: [Link]. Accessed April 21, 2019.

19. Lochner, Lance (2007). Education and crime, University of Western Ontario, 5(8), 1-14. Available at: [Link].

20. Local Area Unemployment Statistics Map. U.S. Bureau of Labor Statistics. Available at: [Link]. Accessed April 23, 2019. 